magnetism. ${ }^{1}$ I am not aware that anything corresponding with recalescence has been observed in the case of nickel. Experiments have been tried, and gave a negative result, but the sample was impure; and the result may, I think, be distrusted as an indication of what it would be in the case of pure nickel. The most probable explanation in the case of iron, at all events, appears to be that when iron passes from the magnetic to the non-magnetic state it experiences a change of state of comparable importance with the change from the solid to the liquid state, and that a large quantity of heat is absorbed in the change. There is, then, no need to suppose chemical change; the great physical fact accompanying the absorption of heat is the disappearance of the capacity for magnetization.

What explanations have been offered of the phenomena of magnetism? That the explanation must be molecular was early apparent. Poisson's hypothesis was that each molecule of a magnet contained two magnetic fluids, which were separated from each other under the influence of magnetic force. His theory explained the fact of magnetism induced by proximity to magnets, but beyond this it could not go. It gave no hint that there was a limit to the magnetization of iron - a point of saturation; none of hysteresis; no hint of any connection between the magnetism of iron and any other property of the substance; no hint why magnetism di sappears at a high temperature. It does, however, give more than a hint that the permeability of iron could not exceed a limit much less than its actual value, and that it should be constant for the material, and independent of the force applied. Poisson gave his theory a beautiful mathematical development, still useful in magnetism and in electrostatics.

Weber's theory is a very distinct advance on Poisson's. He supposed that each molecule of iron was a magnet with axes arranged at random in the body; that under the influence of magnetizing force the axes of the little magnets were directed to parallelism in a greater degree as the force was greater. Weber's theory thoroughly explains the limiting value of magnetization, since nothing more can be done than to direct all the molecular axes in the same direction. As modified by Maxwell, or with some similar modification, it gives an account of hysteresis, and of the general form of the ascending curve of magnetization. It is also very convenient for stating some of the facts. For example, what we know regarding the effect of temperature may be expressed by saying that the magnetic moment of the molecule diminishes as the temperature rises, hence that the limiting moment of a magnet will also diminish; but that the facility with which the molecules follow the magnetizing force is also increased, hence the great increase of $\mu$ for small forces, and its almost instantaneous extinction as the temperature rises. Again, in terms of Weber's theory, we can state that rise of temperature enough to render iron nonmagnetic will not clear it of residual magnetism. The axes of the molecules are brought to parallelism by the force which is impressed before and during the time that the magnetic property is disappearing; they remain parallel when the force ceases, though, being now nonmagnetic, their effect is nil. When, the temperature

\footnotetext{
I I have only recentiy become acquainted with the admirable work of M. Osmond on recalescence. He has examined a great variety of samples of steel, and determined the temperatures at which they give off an exceptional amount of heat. Some of his results are apparent on my own curves, though I had assumed them to be mere errors of observation. For example. referring to my Royal Society paper, there is, in Fig. 38 , a hint of a second small anomalous point a little below the larger one. And, comparing Figs. $3^{8}$ and $3^{8 \mathrm{~A}}$, we see that the higher the heating, the lower is the point of recalescence; both features are brought out by $M$. Osmond The double recalescence observed by $\mathrm{M}$. Osm 'nd in steel with a moderate quantity of carbon I would explain provisionally by supposing this steel to be a mixture of two kinds which have different critical temperatures. Although M. Osmond's methed is admirable for determining the temperature of recalescence, and whether it is a single point or multiple, it is not adapted to determine the quantity of heat liberated, as the small sample used is inclosed in a tube of considerable mass, which cools down at the same time as the sample experimented upon.
}

falling, they become again magnetic, the effect of the direction of their axes is apparent. But Weber's theory does not touch the root of the matter by connecting the magnetic property with any other property of iron, nor does it give any hint as to why the moment of the molecule disappears so rapidly at a certain temperature.

Ampère's theory may be said to be a development of Weber's: it purports to state in what the magnetism of the molecule consists. Associated with each molecule is a closed electric current in a circuit of no resistance; each such molecule, with its current, constitutes Weber's magnetic molecule, and all that it can do they can do. But the great merit of the theory--and a very great one it is-is that it brings magnetism in as a branch of electricity ; it explains why a current makes a magnetizable body magnetic. It also gives, as extended by Weber, an explanation of diamagnetism. It, however, gives no hint of connecting the magnetic proporties of iron with any other property. Another difficulty is this: When iron ceases to be magnetizable, we must assume that the molecular currents cease. These currents represent energy. We should therefore expect that, when iron ceased to be magnetic by rise of temperature, heat would be liberated ; the reverse is the fact.

So far as I know, nothing that has ever been proposed even attempts to explain the fundamental anomaly. Why do iron, nickel, and cobalt possess a property which we have found nowhere else in nature? It may be that at lower temperatures other metals would be magnetic, but of this we have at present no indication. It may be that, as has been found to be the case with the permanent gases, we only require a greater degree of cold to extend the rule to cover the exception. For the present, the magnetic properties of iron, nickel, and cobalt stand as exceptional as a breach of that continuity which we are in the habit of regarding as a well proved law of Nature.

\section{NOTES ON A RECENT VOLCANIC ISLAND IN THE PACIFIC.}

I N I867, H.M.S. Falcon reported a shoal in a position in about $20^{\circ} 20^{\prime} \mathrm{S}$., and $175^{\circ} 20^{\prime} \mathrm{W}$., or 30 miles west of Namuka Island of the Friendly or Tonga Group.

In 1877 smoke was reported by H.M.S. Sappho to be rising from the sea at this spot.

In 1885 a volcanic island rose from the sea during a submarine eruption on October I4, which was first reported by the Janet Nichol, a passing steamer, to be 2 miles long and about 250 feet high.

The U.S.S. Mohican passed it in 1886, and from calculation founded on observations in passing, gave its length as $1 \frac{4}{30}$ miles, height 165 feet. The crater was on the eastern end, and dense columns of smoke were rising from it.

In 1887 the French man-of-war Decres reported its height to be 290 feet.

In the same year an English yacht, the Sybil, passed it, and a sketch was made by the owner, H. Tufnell, Esq., which is here produced.

The island has now been thoroughly examined and mapped, and the surrounding sea sounded by H.M. surveying-ship Egeria, Commander Oldham.

It is now $\frac{1}{10}$ mile long, and $\frac{9}{10}$ of a mile wide, of the shape given in the accompanying plan. The southern portion is high, and faced by cliffs on the south, the summit of which is I 53 feet above the sea. A long flat stretches to the north from the foot of the hill.

The island is apparently entirely formed of ashes and cinders, with a few blocks and volcanic bombs here and there, especially on the verge of the hill.

Under the action of the waves, raised by the almost constant south-east winds, this loose material is being rapidly removed; continual landslips take place, and Commander Oldham is of opinion that the original 
By ï. Tufnell, Esq., I887, bearing S.E. about 2 miles.

By "Egeria," 1889, bearing E. $\mathbf{1} \frac{1}{2}$ mile.

By "Egєria," 1889, bcaring N.N.W. $\frac{1}{2}$ W. I mile.

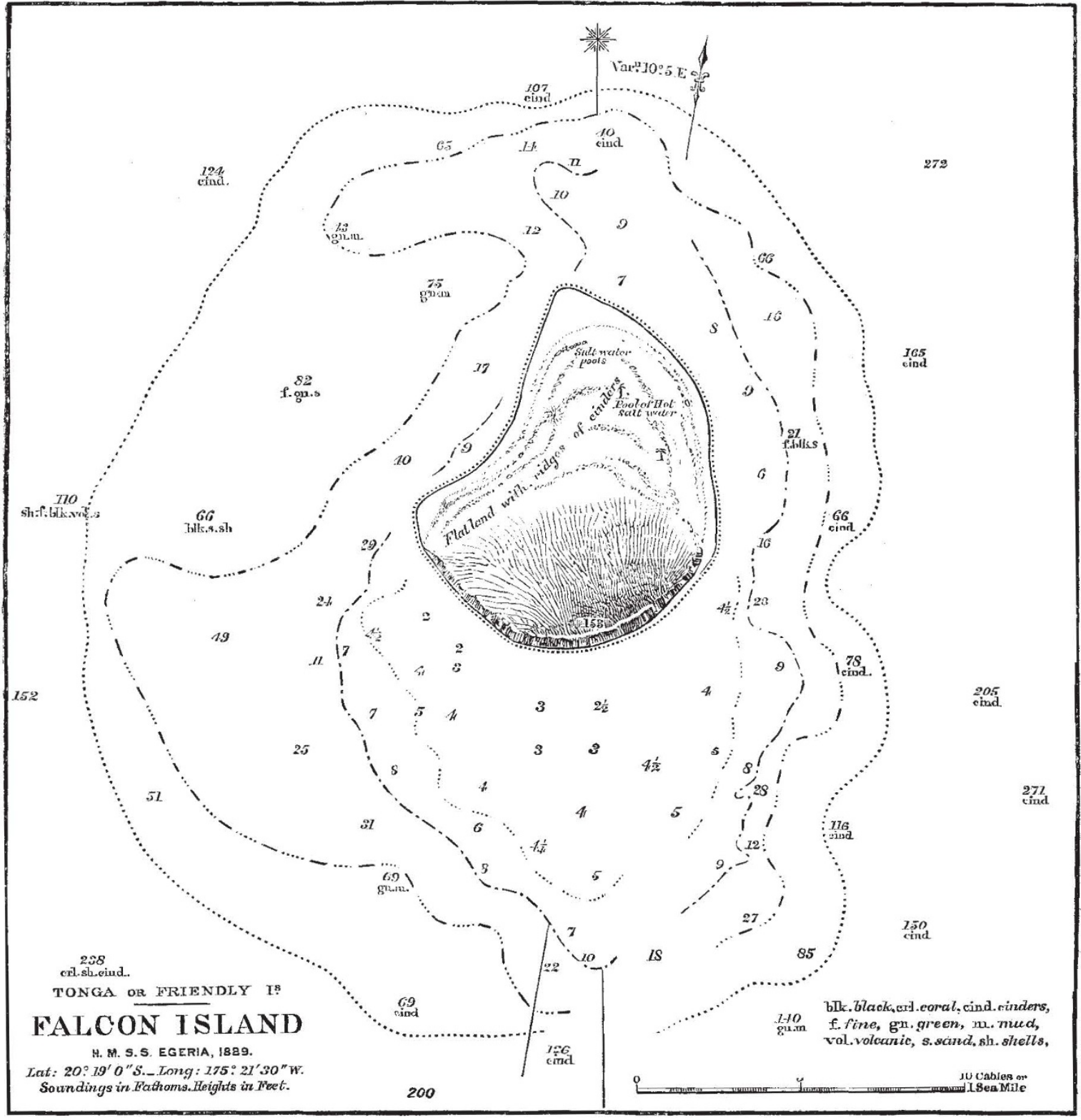


summit was some 200 or 300 yards southward of the present highest cliff, and that the shallow bank stretching to the south represents the original extension of the island.

As far as can be judged from Mr. Tufnell's sketch from the north-west and that of the Egeria from the southsouth-east, considerable changes have taken place in two years, the different summits shown in the former having disappeared as the sea has eaten away the cliffs.

The flat to the north seems to be partly due to redistribution under the lee of the island of the material removed from the southern face. It is crossed by curved ridges from 3 to 12 feet high, which Commander Oldham considers to have been formed as high beaches during spring tides and strong winds, the flat ground between them, almost at the level of the water, being deposited under normal conditions of weather.

The island is thus gaining on one side, while losing on the other, but when the high part has gone, this partial recovery will probably cease.

A little steam issuing from cracks in the southern cliffs was the sole sign of activity, but a pool of water at a temperature of from $9 \mathrm{I}^{\circ}$ to $\mathrm{II} 3^{\circ} \mathrm{F}$., water which rose in a hole dug in the flat of a temperature of $128^{\circ} \mathrm{F}$., and a temperature of $100^{\circ} \mathrm{F}$. in a hole dug half-way up the slope, also show that the island still retains heat near the surface. The water is sea-water that has filtered through the loose ashes, and it rose and fell with the tide.

It appears by the condition of the flat that the island has neither risen nor subsided during the past two or three years.

It will be interesting to watch the ultimate fate of this last addition to the Pacific isles, but it seems probable that its existence as an island will be short unless a hard core is yet revealed.

The soundings between Falcon Island and Namuka show that they are separated by a valley 6000 feet deep.

Metis Island, 73 miles north-north-east of Falcon Island, is another volcanic cone that appeared a few years before the latter, but has not yet been examined.

W. J. L. WHARTON.

\section{WEATHER FORECASTING.}

\section{$\mathrm{P}$} PULAR interest in weather prediction shows no sign of abating. The January number of the Kew Bulletin is devoted to an account of Herr Nowack's socalled "weather plant," and its failure as an indicator either of coming weather or of earthquakes. Very recently a lively correspondence has been carried on in the daily press on the merits or demerits of the forecasts issued by the Meteorological Office. Accordingly, some remarks on the subject in the columns of NATURE may not be out of place.

One critic says that the forecasts are little better than haphazard guesses, and that the money devoted to them would be better spent on an additional lifeboat or two on the coast. Another says the forecasts are not worth the paper they are printed on, and wishes that the Office published in the newspapers fuller accounts of the weather reported from the coasts.

The fact is that the Office is compelled by public opinion to issue forecasts. The public will have its forecasts, as in 1867 it would have its storm-warnings, notwithstanding the reluctance of meteorologists to issue either the one twenty years ago or the other at present. It can hardly be doubted that, for these islands at least, conscientious meteorologists would be disposed to agree with Arago, who said in $\mathrm{I} 846$, and printed it in italics in the Annuaire du Bureau des Longitudes: "Jamais, quels que puissent être les progrès des sciences, les savants de bonne foi et soucieux de leur réputation ne se hasarderont à prédire le temps." We are, of course, speaking of forecasts based on telegraphic reports, and emanating from a central office. In every country, without exception, where forecasts for distant counties or provinces are issued from headquarters, the complaints from outlying stations, of occasional failure, are frequent enough.

The fact is that at individual stations the percentage of success may be highly satisfactory, as at Mr. C. E. Peek's observatory at Rousdon, Lyme Regis. The results for this point appeared in the Times of January I4, and are as follows:-

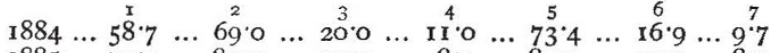

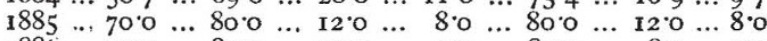

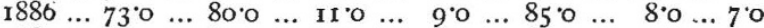
$\begin{array}{llllllllllllllll}1887 & \ldots & 75^{\circ} 0 & \ldots & 83^{\circ} 0 & \ldots & 9^{\circ} 0 & \ldots & 80^{\circ} & \ldots & 82^{\circ} 0 & \ldots & 110^{\circ} & \ldots & 7^{\circ} 0\end{array}$

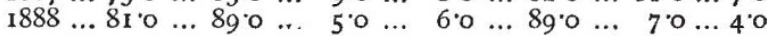

In this, Col. I is percentage of reliable wind and weather.

$\begin{array}{lll}\text { Col. } 2 & , & \text {,' wind only. } \\ \text { Col. } 3 & , & \text { wind doubtful. } \\ \text { Col. } 4 & \text { wind unreliable. } \\ \text { Col. } 5 & \text { ", } & \text { reliable weather. } \\ \text { Col. } 6 & \text { weather doubtful. } \\ \text { Col. } 7 & , & ,\end{array}$

On the other hand, at other points the forecasts may be frequently unsuccessful.

In one important particular not only our own Office, but all other Offices in Europe, signally fail, and that is the quantitative prediction of rain. No one is able, apparently, to predict whether the amount of rainfall on the morrow will be a tenth of an inch or a couple of inches. No sudden floods have ever yet been foretold. By this we are not speaking of predicting the approach of floods to the lower valleys from rain which has already fallen on the upper reaches of a river, for that is not meteorological prediction at all.

With the necessarily incomplete character of the information reaching head-quarters, the wonder is that the Office can attain such success as it does. The main deficiency in the information is in its quantity, and this seems to lie at the door of the Postal Telegraph Office, which insists on being paid for its telegrams. If meteorological messages were transmitted gratis, we might expect to hear at frequent intervals from our outposts, instead of twice, or, at most, thrice in the twenty-four hours : in fact, from several stations we can only hear once, the cost of more telegrams being prohibitive. It is selfevident that such an amount of information is quite insufficient. The weather will not abstain from changing because the hour for a telegraphic report has not arrived.

The information contained in the telegrams is also deficient in quantity, for the reporters cannot, within the prescribed form of their messages, communicate all the impressions which the ever-varying appearance of the sky may have conveyed to their minds. A skilled cloud observer, who has leisure to practise his powers, is often able to form a very correct idea of what is coming for the region bounded by his own horizon, but he is quite unable to give the benefit of his observations and experience to a friend in another county by telegraphing the information.

The greatest want which the Office finds in its observers is skill in cloud observation, and it appears to be the case that a cloud observer nascitur non fit, and that it is next to impossible to teach the art to a new hand, at least by correspondence.

Instrumental records of the phenomena taking place in the higher strata of the atmosphere are of course unattainable, and it is only by carefully watching the upper clouds that we can gain any notion of changes taking place up there, but, by means of such watching, Mr. Clement Ley is able to predict with nearly perfect certainty the weather for the Midlands-his own neighbourhood. 